\title{
Barriers and breakthroughs:
}

Engaging in socially just ways towards issues of Indigeneity, identity, and whiteness

in

Teacher Education

\section{Tasha Riley, Sue Monk, \& Harry Van Issum}

Author 1: Education and Professional Studies, Griffith University, Brisbane, Australia

Email address: t.riley@griffith.edu.au

Author 2: Education and Professional Studies, Griffith University, Brisbane, Australia

Email address: s.monk@griffith.edu.au

Author 3: Humanities, Griffith University, Brisbane, Australia

Email address: h.vanissum@griffith.edu.au

\section{Acknowledgement}

The context for this study is set within the traditional country of the Yugarabul, Yuggera, and Jagera peoples. We acknowledge that they are the traditional custodians and appreciate their blessing to conduct our work and study upon their traditional lands. 


\begin{abstract}
Within Australia, The Australian Professional Standard for Teachers' Standard 1.4 dictates that teachers should have an understanding and awareness of the histories, cultures and languages of Aboriginal and Torres Strait Islander peoples. Yet nonIndigenous teachers seem reluctant to integrate Indigenous perspectives in the classroom. This study examines how 142 pre-service teachers' views on a first year Indigenous Education course founded upon a social justice/antiracist framework evolved throughout their first term. The article focuses upon specific aspects of the course that pre-service teachers identified as enabling them to move beyond resistance and towards understanding and confidence in relation to their ability to teach issues related to Indigeneity, whiteness, and identity in their own classrooms. Based on preservice teacher responses, we provide considerations for the development of future courses addressing Indigeneity in relation to design, implementation and collaboration.
\end{abstract}




\section{Introduction}

In Australia, a significant gap exists between the achievement of Indigenous and nonIndigenous learners. Indigenous students are over represented within special education programs (DiGiacomo, Davidson, Abbott, Delaney, Dharmendra, McGrath, and Vasquez 2013; Sweller, Graham, and Van Begen 2012), and are more likely to face inequities than their non-Indigenous peers (Francis, Mill, \& Lupton 2017; Ford 2013). Studies demonstrate that teachers have lower expectations of Indigenous students than their non-Indigenous peers (Riley, 2018, 2012; Dandy, Durkin, Barber, and Houghton 2015; Rubie-Davies, Hattie and Hamilton 2006). Indigenous scholars claim that teachers' deficit perceptions stem from a history of exclusionary practices and policies, ensuring that Indigenous peoples remain largely unseen within the educational environment (Herbert 2006; Sarra 2011; Nakata 2007), and that until these inequities are exposed, a gap between the achievement of Indigenous and nonIndigenous students will remain.

Various approaches have attempted to alleviate this imbalance. The Australian Professional Standard for Teachers' Standard 1.4 dictates that teachers should have an understanding and awareness of the histories, cultures and languages of Aboriginal and Torres Strait Islander peoples (see http://www.aitsl.edu.au/australianprofessional-standards-for-teachers) (AITSL 2011), yet non-Indigenous teachers seem reluctant to integrate Indigenous perspectives into the classroom (Riley \& Pidgeon, 2018; Riley, 2014; McLaughlin and Whatman 2015). Van Issum (2012) states that there is an unspoken decree that teachers "should not talk about or teach the myriad of Aboriginal and Torres Strait Islander issues for fear of breaking taboos and thereby causing offence" (55). While it is critical to acknowledge the positive influence of 
Indigenous teachers upon their Indigenous learners (MATSITI 2015) and to ensure that more Indigenous teachers, principals, and policy makers work with and within the educational system (Pidgeon 2016; Sarra 2011), this does not abrogate nonIndigenous teachers' responsibility to develop better understandings of Indigenous studies, and thereby have a positive impact upon Indigenous learners.

Thus it is increasingly relevant to ensure opportunities exist for pre-service teachers, the majority of whom are young, 'white' ${ }^{1}$, middle-class females (McKenzie, Weldon, Rowley, Murphy, and McMillan 2014; Weldon 2015; Santoro 2009), to identify "the ways in which their racial ascription and social positioning inform their actual practices and interactions with students" (Solomon, et al. 2005, 149). This is crucial given that teachers' judgements are positively influenced by dominant cultural norms (Bianco, et al. 2011), similar values and belief systems (Ford, Grantham, and Whiting 2008), and same group member identity (Karaowsky and Seigel 1995). Tertiary courses founded upon social justice and anti-racist frameworks can be beneficial, providing opportunities for developing critical self-reflective skills (Bennett, Power, Thompson, Mason, and Bartleet 2016; McDowall 2017). Mills and Ballantyne (2016) argue that there is limited information about specific strategies to assist teachers to "engage with student diversity in socially just ways" (263). Burke and Collier (2017) contend, teachers "may accept theories learned and utilized in the post-secondary education courses [however] they are sometimes unsure about how these would work with their students, or if they would be accepted in school environments" (283). Researchers (Schick 2014; St. Denis 2007) discuss resistance from 'white' students when teaching issues related to identity, diversity and/or Indigeneity, topics often addressed within courses founded upon a social justice/anti-

\footnotetext{
1 The term 'white' is a generic term referring to any non-Indigenous person and is not used as a derogatory, oppositional term.
} 
racist framework. Schick (2014) states that the "Politics of resentment found in the refusal of anti-oppressive and anti-racist teaching is produced by and simultaneously produces the on-going effects of white supremacy in schools in the dominant society" (88-89). DiAngelo (2011) notes that many white students have had limited opportunity to develop "the stamina to sustain attention on an issue as charged and uncomfortable as race" (63), hence the need to approach such issues with care. In practical terms, Nakata et al. (2012) contends that, within education courses based on Indigenous issues, the tendency to overemphasize simplistic binary understandings of Indigenous knowledges, as diametrically opposed to Western knowledges, can be counter-productive, alerting us to the possibility that students' resistance may overcome their willingness to engage with complex, challenging issues.

We argue that more focus is required to ensure 'white' pre-service teachers confront their resistance in order to develop confidence in their ability to teach issues like Indigeneity and identity. Teacher educators need to understand the rationale behind this resistance, to develop strategies to decrease anxiety and increase preservice teachers' ability to effectively teach Indigenous issues in their future classrooms. This study's objective was to examine how pre-service teachers' views on a first year Indigenous Education course founded upon a social justice/antiracist framework evolved throughout their first trimester. We sought to understand which aspects enabled students to develop their knowledge, skills and confidence to effectively teach issues of Indigeneity and identity. This will assist in the development of courses which seek to address Indigeneity in relation to design, implementation and collaboration. This is particularly important in Australia, given the recent national curriculum rollout and the ongoing NAPLAN results which contribute to deficit views of Indigenous students. 


\section{Social Justice and Anti-Racism Education in Teacher Education Programs}

Studies demonstrate that teachers make a difference to students' social and educational outcomes (Ainscow 2010; Sutton Trust 2015). Rubie-Davis, Hattie and Hamilton (2006) found that when high expectations were applied, teachers were able to raise students' achievement levels, regardless of their background. Some scholars have argued that misunderstandings relating to culturally affirming teaching practices have reinforced existing Indigenous stereotypes (Rose 2012). This points towards teachers entering schools with outdated information that "trivialise, distort, misunderstand, misuse and romanticise Indigenous knowledge and systems of thought" (Nakata et al. 2012, 128). This misinformation is passed to a new generation of learners, and has a negative impact upon Indigenous learners' self-esteem (Sarra 2003). Nakata et al. (2012) argue that Indigenous studies courses prioritizing action as Indigenous practice over more theoretical understandings give the impression that Indigenous people are incapable of theoretical understandings, contributing to deficit perspectives of their ability and potential. Leonardo and Porter (2010) provide insight into different perceptions of "race dialogue" and make important distinctions between "anti-intellectual...[and] anti-intellectualist" (150). They show how such conversations leave whites satisfied with the intellectual discussion but no further informed about the lived experiences of people of colour.

A strategy for addressing such issues is to develop courses under a social justice framework based on teachers' beliefs and perspectives, however teacher educators often report tensions arising as pre-service teachers reflect upon how personal beliefs and biases influence diverse students (Solomon, et al. 2005; Gillespie, Ashbraugh, and DeFiore 2002). Schick (2000) describes how 'white' 
female teachers, while eager to learn about Indigenous history, become increasingly resistant towards discussion of white privilege. This reaction, Schick claims, may arise from a deep-seated "saviour mentality", stemming from a history of colonialism and advantage. Other scholars (Van Issum 2019; Burke and Collier 2017; Solomon, et al. 2005) observe that pre-service teachers self-regulate their responses due to fear of offending or being perceived as racist.

DiAngelo (2011) describes white students' reluctance or refusal to acknowledge the pervasiveness of racial oppression, and how white/colonial identities are implicated in this oppression as "white fragility", a condition "in which even a minimum amount of racial stress becomes intolerable, triggering a range of defensive moves" (57). As DiAngelo explains, within a settler-colonial context, most white people have had limited opportunities to develop the cognitive or affective skills required to engage in nuanced discussions about race, "Pointing out white advantage will often trigger patterns of confusion, defensiveness and righteous indgination" (p.64). The positioning of some white pre-service teachers as the victims of antiracist efforts by their refusal to acknowledge how white/colonial indentities are implicated in the ongoing effects of racial opression and/or a refocusing of attention to their own perceived mistreatment could be regarded as an attempt to "reinstate white racial equilabrium" (DiAngelo 2011, 57).

Leonardo and Porter (2010) provide further insight into these uncomfortable encounters by drawing attention to the inherent contradiction in the concept of a 'safe space' for discussions about race, whiteness and colonisation. They consider the promotion of a " 'risk' discourse about race, which does not assume safety but contradiction and tension." (139), which allows students to confront racial discourse. St. Denis (2007) claims that such, "anti-racist education explores the practices, 
processes, and ideologies of racialization, which includes a study of not only how racism disadvantages some but also how racism advantages others, and how whiteness gets produced and construed as superior" (1087). Teachers familiar with this framework are likely to identify inequity and be adept at responding appropriately (Riley, 2014; Turhan 2010).

This study focuses on student responses to an Indigenous Knowledges course founded upon a social justice/antiracist framework in order to determine what strategies work well. We believe successes and challenges illuminate possibilities for breaking the barriers that undermine socially just pedagogies.

\section{Method}

\section{Positionality}

Critical pedagogy challenges the notion of neutrality within schools, and curriculum and culturally responsive educators expect teachers to be aware of hegemonic classroom practices (Shapra-Lishchinsky 2016). As pre-service teacher educators, we are aware that our position is not neutral (Martin \& Mirraboopa 2003). This study's authors identify as Indigenous Australian, non-Indigenous Australian and Canadian. We come into practice with experiences, biases and judgements which influence the way we see the world and how our students see us. We accept that our position is overlaid with multiple perspectives. Our previous teaching experience influences our passion to view school students as the ultimate beneficiaries of our pre-service teacher education pursuits.

We take a racialized stance in our analysis of a first-year teacher education course, focusing on how notions of Indigeneity are socially constructed. The course was designed to provide pre-service teachers with opportunities to speak about 
difficult and emotionally charged topics such as discrimination, racism, colonialism and oppression. The course was developed and convened by the authors, and whilst the pre-service teacher cohort was racially and ethnically diverse, participants consisted primarily of young, white, female teacher candidates, representative of Australia's current teaching population (McKenzie, Weldon, Rowley, Murphy and McMillan 2014). While critical race pedagogy is inherently risky, white pre-service teachers may find themselves particularly unsettled, given that "pedagogies that tackle racial power will be most uncomfortable for those who benefit from that power" (Leonardo and Porter 2010, 140). In the following section we analyse pre-service teachers' responses towards course content and structure in order to critically appraise the white normative position, as well as some of the racialized assumptions underpinning the course design.

\section{The Study}

The study focuses on the responses of first-year pre-service teachers enrolled in the foundation year of the Bachelor of Education Program at an Australian university, and outlines responses to a questionnaire related to a mandatory course on Indigenous Knowledges. The research questions pertinent to this study are:

- What were pre-service teachers' responses towards attending a course related to Indigeneity and identity?

- In what ways did pre-service teachers' attitudes towards the issues addressed in the course evolve throughout the duration of the course? 
- How did white pre-service teachers' responses demonstrate a willingness to confront whiteness?

- What aspects of the course did pre-service teachers identify as enhancing and/or impeding their understanding of the issues addressed, and their ability to pass on this information in their prospective classrooms?

As teacher educators we believe that an important goal for teachers is to think critically about the social context in which they teach. Within our course syllabus we contend that teaching is "an inherently political and moral enterprise" (Authors, course profile, 2017), given the significance of teachers on students' academic outcomes and wellbeing (Hattie, 2012). Throughout the course, teachers were asked to consider the on-going influence historical and contemporary manifestations of racism have had upon Indigenous peoples. This was emphasised by inviting Indigenous people as guest speakers to contexualise the issues. In weeks 1-4, we discussed how governmental policies had effectively denied Aboriginal peoples of basic human rights - the right to land (Harris 1994; Kelly \& Lenthall 1997), human and legal status (Allen 1988; Kidd 1994), and families - through the forcible removal of Indigenous children (Wilson 2003; Martin 2003). Weeks 5-8 detailed contemporary manifestations of racism, and the on-going effects policies and events have over dominant societal perceptions towards Indigenous peoples. In weeks 9-12 we discussed how arts practices are a powerful way to learn and teach how identities are constructed, represented and challenged. We showcased a number of Indigenous artists to challenge deficit representations of Indigenous peoples. For the final assessment, pre-service teachers were invited to create a video using an example of Indigenous art which reflected the concepts discussed in class. Specific objectives of 
the course were to: (1) encourage critical discussion and reflection around issues related to Indigeneity and identity; (2) provide opportunities for candidates to develop confidence and competency in relation to teaching, analysing, comparing, distinguishing and justifying these issues in their future classrooms; (3) highlight how the arts and narrative may be used as educational tools, challenging inequity and deficit mindsets; and (4) create collaborative working relationships between Indigenous and non-Indigenous staff and community members.

The course used a mixed modal structure involving one week of face-to-face lectures followed by one week of course work online. The face-to-face lectures were followed by 3 hour tutorials of 25-30 students. Our tutorial learning activities were informed by Schneidewind and Davidson's (2014) Open minds to Equality: A sourcebook of learning activities to affirm diversity and promote equity, Fourth Edition and a text by Harrison and Sellwood (2016) Learning and teaching in Aboriginal and Torres Strait Islander Education, Third Edition. The course also contained one 2-hour workshop per fortnight, co-facilitated with convenors of a 'partner' course on social issues in education.

Participants were solicited through a 'call for participation' letter provided to students in their final tutorial. Ethical protocols ensured participation was voluntary, data was unidentifiable and only accessible after final grades had been posted. Of the 539 students enrolled, 142 students volunteered to participate. Participants' responses to the issues of Indigeneity and identity were considered in this paper; a) what aspects of the course they found worked well; and b) what aspects of the course were a challenge.

\section{Data Analysis}


After course completion, the qualitative data set was transcribed and collated for analysis. A table including participants' responses was created and researchers reviewed survey responses. An inductive and emergent process (Cresswell 2012; Merriem and Tisdell 2016) was used to analyze the responses. In order to develop a more reliable understanding of pre-service teachers' interpretations and observations of the course, survey transcripts were initially read and coded by "line-by-line analysis" (Strauss and Corbin 1998, 119) for emergent themes. An open coding process enabled findings to emerge directly from the data, and reviewers grouped recurring ideas and concepts into emerging themes.

Several emerging themes were identified: (a) resistance (due to fear of offending; relatable/non-relatable content); b) breakthroughs (strategies enhancing growth); c) barriers (structural barriers impeding growth). A coding list (Rubin and Rubin 2005) was created to ensure each researcher could identify and label participant's responses according to the coding definition. To ensure consistency in identified themes, each researcher used the aforementioned coding structure to individually code participants' responses. Inconsistencies relating to the coding identification process were discussed until consensus was reached.

\section{Findings and Discussion}

\section{Resistance}

\section{Fear of offending}

Various scholars (Ladson-Billings 1999; Marx 2006; Schick and St. Denis 2005) have noted resistance when educators discuss issues of race and racism, particularly with a 
group of 'white' people. While we promoted an environment where, as Marx (2001) suggests, participants are "encouraged to share their true feelings, no matter how 'politically incorrect' they seemed to be" (8), students' responses revealed reluctance to open up during discussions for fear of "getting it wrong" (McLaughlin and Whatman 2015) and/or offending their peers. This was particularly true for nonIndigenous students, who noted this as their primary reason for not engaging. Two participants stated:

I found it particularly challenging as I am not Aboriginal [sic] or Torres Strait Islander and I felt very uncomfortable when it came to talking about particular things or I just would not speak up as I felt as if I might offend someone.

I found discussing topics about Aboriginal and Torres Strait Islander people was difficult as I am very ignorant $[\ldots .$.$] about their culture. I also found it$ difficult as there were people of this [descent] in the classroom and I didn't want to offend anyone just because I had no idea.

Some suggested that in order to feel comfortable speaking in class they would want instructions noting precisely "what we can and should not say in discussion of Aboriginal or Indigenous background". Given the violence that characterized the colonization of this country and the sensitive nature of black/white relations, students' reluctance was understandable. Leonardo \& Porter (2010) argue that since race talk will always be unsafe for people of colour, there is a need for emotional pedagogical approaches which challenge white students to perform a "humanizing violence" (146), requiring them to unpack and challenge taken for granted norms. White 
students can no longer hide behind a safe notion of 'possibly offending someone'. Leonardo \& Porter (2010) contend that, "authentic race discussions are violent to whites for the very reason that such discussions would expose their investment in race, their full endorsement of, rather than flippant regard for it." (150). As educators, we were aware that our discussions would make students uncomfortable, however, clearly they are necessary in order to enable pre-service teachers to gain the skills to transition from university training concerning Indigenous content and pedagogy to classroom practice. Given this, we introduced the concept of a "confirming environment", or a "safe space", implying a place where one may fully express oneself without fear of feeling uncomfortable. Given the nature of our course, we explained that many of the issues would potentially create feelings of discomfort, particularly as students would be invited to reflect upon their position around issues of white fragility and racial discourse.

Some participants remarked that apprehension about more difficult concepts created a barrier in tutorial discussions, which as various researchers (Tatum 1999; Marx 2001) claim, could be detrimental to pre-service teachers' understandings of these issues. Tatum (1999) suggests that, in order for people to become more aware of the influence of race and racism within society, they must be willing to "talk about it" (17). In fact, it was white pre-service teachers' discomfort in relation to their fear of offending that their Indigenous peers felt influenced their own discomfort. One Indigenous participant stated:

For me, as a Torres Strait Islander, I found it more challenging to see people find themselves uncomfortable to speak up, because they believe that I might 
take it offensively. I felt sometimes that if I was not there, the people in my class would feel more willing to answer.

This participant's response reveals the power of white privilege. White students' cursory glances around the class appeared not to be seeking approval from peers, but more 'without Indigenous presence, I may speak more freely', potentially avoiding a situation where they may offend people of colour. The Indigenous participant felt that she inhibited discussion rather than being free to critique unwilling participants, thus supporting Leonardo and Porter's (2010) claim that "Mainstream race dialogue in education is arguably already hostile and unsafe for many students of color whose perspectives and experiences are consistently minimized" (149). Indigenous students could interpret their white peers' refusal to participate in difficult dialogue as ambivalence or dismissal. Leonardo and Porter (2010) contend that while white people may fear being exposed as racist, minorities' fears tend to relate to an unfilled hope for change, so the Indigenous student's awareness of her white peers' refusal to engage in authentic race dialogue represents an on-going pattern of disappointment instigated by white people. This participant's statement also helps to illustrate how white pre-service teachers have the privilege of avoiding racialized discussions which may cause discomfort in the classroom. Indigenous students who feel uncomfortable also may be less inclined to participate if they feel their presence inhibits classroom discussion, or that their teacher may be unable to support them in challenging situations. Indigenous students may feel its their duty to 'speak up for their people', placing undue pressure on students who already feel isolated in a white dominated tutorial, perhaps resulting in withdrawal or absenteeism. The data set indicates that as 
educators, white teachers need tools to deal with difficult discussions around race and identity, whilst simultaneously allowing students to feel supported and encouraged.

\section{Challenges due to relatable/non-relatable course content}

Pre-service teachers were asked to critically reflect upon Indigenous perspectives in relation to historical, social and political events. Students were introduced to course readings from Indigenous creative artists from around the world, ensuring that they had a 'bank' of Indigenous knowledge. Indigenous participants stated they appreciated the relatable course content; as this Indigenous participant noted, "A lot of the knowledge taught directly relates to me as an Aboriginal woman". However, Indigenous participants also noted that the content was challenging because of its familiarity:

Part of this course worked well for me as I am Indigenous to New Zealand and relate to a few of the issues dealt with in the course such as cultural diversity, beliefs and values. [...] I found it more difficult when discussing topics such as the Stolen Generation and lack of Treaty because of the hard time this culture has been through. It was challenging to know the mistreatment they faced $[\ldots]$ and is followed by massive effects to this day.

While some Indigenous participants noted appreciating group discussions, they also were aware that non-Indigenous peers regarded the course content as difficult because of their inability to relate to the discussion. One participant stated: 
It was interesting to see other people's views and opinions on sensitive subject matter such as race and appropriation. It was also interesting learning how much people know about my culture such as the Stolen Generation and other atrocities.[...] I personally didn't have this issue but I did hear discussions that some people did have trouble relating the content to their own lives.

This may have been the first opportunity for both Indigenous and non-Indigenous participants to attend a course primarily focused on Indigenous content. While this may have been refreshing for some, others felt uncomfortable and frustrated. One assessment item encouraged pre-service teachers to reflect upon their ethnicity and personal history in relation to the stories and perspectives within course readings, which some white pre-service teachers found challenging:

I found this course particularly difficult as I am not a person of Indigenous descent. [...]. The assessment for this course was very presumptuous and prejudiced as not all people can relate topics back to Indigenous culture and values. As a Caucasian, middle-class women of British descent, I found it hard to determine what the task was asking me to do.

The task requiring us to identify and discuss my own cultural and ethnic identity also made it difficult to then relate these to the text book, as I cannot personally relate to the $[\ldots .$.$] issues discussed in the text.$

These comments are ironic, considering course discussions of how an Australian educational system based on a Western framework was a deterrent for many 
Indigenous students, who could not relate to curriculum and assessment tasks. Kidman, Ormond, and MacDonald (2018) argue that white superiority is often covertly embedded into educational environments where "acts of brutality and invasion are transformed into patriotic tales of settler and pioneer heroism" (234). Many pre-service teachers acknowledged being unaware of the brutality that had occured against Indigenous peoples since Invasion Day on January 26, 1788, or even that the notion of 'discovering' Australia existed (Harrison \& Sellwood 2016). It may be that the Eurocentric traditions of education are a safe zone for white students, and content based on Indigenous issues and values is increasingly confronting.

Conversely, many white pre-service teachers acknowledged that, while not accustomed to a primarily Indigenous focused course, they appreciated it precisely for this reason, noting how this knowledge might enhance their future teaching practice:

Being exposed to the counter narrative shared from the Indigenous and Torres Strait Islander community through course readings and guest speakers has been invaluable. Such interactions have helped me to gain a greater sense of understanding and knowledge [....]. I strongly feel that such learning and reading must be included in the curriculum.

However, some white pre-service teachers found the course frustrating for the same reason, and dismissed it as feeding into a particular agenda:

While I understand the need to respect Aboriginal and Torres Strait Islander individuals, this increase in focus has somewhat disconcerted me. I never 
intended to treat any child with disrespect, but this new overarching political correctness movement is, to me, a perpetuation of segregation type behaviour.

It is interesting that courses have historically been dominated by British history and Western values, whereas this course was careful to demonstrate the Indigenous counter-narrative and hence, 'balance the ledger'. Some students saw this as an attempt to further segregate black and white perspectives and remarked on feeling affronted when it came to discussions of white privilege or more direct instances of racism. One white pre-service teacher noted:

I found a particular newspaper article extremely difficult to read as it started with saying: you know you're in Australia when (insert examples of racism). [...] There are examples of racism seen in Australia, as there are on every continent in the world, but that doesn't mean Australia as a whole is a racist country. I am aware that this is someone's opinion and they may have experienced severe discrimination to reach this conclusion. [...] I just personally didn't enjoy being introduced to an article that generalises my country and its people as something that is so negative.

Yet, by disregarding the description of incidents of racism as 'opinion', the inherent privilege of the white pre-service teacher is revealed. It becomes apparent that this participant is referring to "my country", detached from any unsavoury racial events. As Leonardo and Porter (2010) insist, these are the very conversations that are needed, away from the defensive attitudes and 'safe zones', conversations that confront the privileged position of white pre-service teachers. 
In addition, difficulties for some white pre-service teachers stemmed from disappointment in their white colleagues, who they thought unwilling to make the effort to better understand the diverse needs and experiences of their future students. As this participant noted:

What I found challenging was the fact that others would make these cultural issues about themselves instead of looking at the bigger picture and realizing that we need to be a part of a cultural change.

Some of these perspectives are drawn from ideals that appear to state that "it's not their problem and they are unlikely to teach Indigenous students anyway". Clearly such sentiments fail to understand the key tenets of the Australian Professional Standards for Teachers, which specifically deal with Indigenous students and issues.

These comments reflect the complexity of emotions experienced by first-year pre-service teachers in courses addressing issues of Indigeneity and identity, and illustrate the range of issues teacher educators must address. As educators already privy to the various kinds of resistance these courses incite, we implemented a number of strategies, each with varying degrees of success. The next two sections describe the strategies participants thought worked well in relation to these issues, and those which needed further consideration.

\section{Breakthroughs: Strategies enhancing growth}


While many participants discussed their initial resistance, as the course continued they noted that they began to feel more comfortable engaging in critical discussions. Participants acknowledged a number of different strategies that helped them overcome their initial resistance, as described below.

\section{Making it about the students}

DiAngelo (2011) contends,

The continual retreat from the discomfort of authentic racial engagement in a culture infused with racial disparity limits the ability to form authentic connections across racial lines, and results in a perpetual cycle that works to hold racism in place (66).

As schools in Australia become increasingly diverse, teachers are required not only to know about these issues but also be able to provide informed discussions about them with their students. Given that "White people often need to reflect upon racial information and be allowed to make connections between the information and their lives" (DiAngelo 2011, 67), rather than avoid conflict, pre-service teachers were invited to interrogate their discomfort in relation to issues of race and white privilege, through written reflections, peer-to-peer dialogue, and small group discussions. It was pleasing to see how the students' learning evolved through having the opportunity to use their social and cultural lens to observe and analyse.

One pre-service teacher noted how feelings of guilt or shame inhibited their engagement, however, she also noted that this was not conducive for her future practice and that she needed to move beyond debilitating emotions. To support our teachers, we also incorporated discussions and readings from Indigenous and nonIndigenous scholars such as Bishop (2012), Sarra (2011), and Harrison and Sellwood 
(2016), who reiterate the positive influence high expectations and caring practices can have upon all students' success. By incorporating a range of voices through our course readings, we wanted to raise awareness of the successes and ongoing commitment of many educators in redressing injustice and disadvantage.

Encouraging pre-service teachers to think about specific things they might do to ensure their classrooms were equitable socially just spaces made it easier for them to engage in difficult conversations, as the following comments reveal:

I had not realised the implications these concepts had on real life events, such as cultural appropriation. I had not considered the sensitivity certain cultures may have $[\ldots .$.$] , and how I should be careful and respectful to different cultures$ and cultural symbols. It is not my attitude towards these concepts and issues that matters, it is the Indigenous perspective that matters most and [should] be taken into consideration much more.

It was interesting to me that through engagement with the course content, I often found myself re-evaluating my daily actions and thought processes. This led me to imagine the students in my future classrooms and how I would need to treat them equitably, rather than equally, as I had previously assumed.

Encouraging pre-service teachers to analyse their engagement and reactions, and asking them to consider specific strategies they might employ to ensure their classrooms were welcoming environments for all students, seemed to shift notions of Indigenous students as 'children who need to be saved', positioning them as determined, capable individuals; and positioning pre-service teachers as equally 
agentic. As one participant said, "how to fight alongside them rather than just feel sorry for them."

\section{Collaborative learning through group work}

Burke and Collier (2017) observed how teacher inquiry groups can be useful for engaging teachers in complex issues as "a way forward to consider the dilemmas that teachers commonly face in classrooms every day" (283). We encouraged pre-service teachers to work together when discussing how they might address various inequities in their classrooms. Participants reported finding these conversations valuable, providing unfamiliar viewpoints, as these students explained:

Group discussions in tutorials have been some of the most intriguing and engaging times this trimester. When we have discussions about these topics of differences and identity there are so many standpoints and perspectives that come out.

The ability to be able to have open discussions, where everybody was respectful of other people's opinions and nobody was judged for their opinion was something I think worked well.

White pre-service teachers remarked on the benefits of sharing work with their Indigenous peers, who increased their understanding of various concepts and themes discussed in class: 
Though it was difficult talking about these topics with Aboriginal people in the class, it was good to learn from them as I was educated from personal experiences and feels [sic] of members of the classroom that I never would have known if they were not in the class.

I found it mostly easy to talk when it came to comparing white Australian identity to that of an Indigenous Australian due to my friends who are of Indigenous or Torres Strait Islander [descent]. They [.... allowed me to look at this course from different perspectives.

While there is benefit in pre-service teachers learning from each other, it is also important to ensure that Indigenous people do not feel pressured to become the “unoffical educator for all things Indigenous" (Bond 2014), an issue which has been noted by Indigenous educators working within the education system (Bond 2014). Assessment requiring students to present an activity specificially related to one of the discussed concepts was one way of increasing prospective teachers' comfort in embedding Indigenous perspectives in the classroom.

Indigenous participants also acknowledged appreciating group discussions, providing more insight into their peers' awareness and perspectives relating to historical and contemporary issues. However, there was awareness of the discomfort the course content could elicit in their non-Indigenous peers. Pre-service teachers remarked that having a tutor who was familiar with course content and was supportive of students made them feel more confident: 
Within this course we explored a variety of concepts that can be challenging to express and hard to talk about. [...] Having a tutor who was reassuring about these issues helped greatly, as I felt more comfortable giving things a go and I was not [too] scared to talk about these sensitive topics.

I found my tutor [tutor's name] to always be very honest about some of the more challenging concepts, like prejudice and racism - explaining them in a factual way without shying [away] from the darkness of them, which was refreshing.

While group work was a way of allowing students to collaboratively confront sensitive and confronting issues, Indigenous tutors provided a glimpse into the consequences of racism and discrimination. Having non-Indigenous tutors provide examples of their experiences as a counter-narrative was also regarded as useful, as they provided pre-service teachers with "real life" situations they may confront in the classroom, helping to navigate the challenge and inherent violence of race talk (Leonardo and Porter 2010).

\section{Arts-based practice}

For the final assessment, students were invited to create a five minute presentation using an arts-based medium to illustrate their understanding of a specific concept. One white pre-service teacher juxtaposed the work of Indigenous artist, Vernon Ah Kee (2002), If I was white, with white Australian artist Charles Meere's 
(1940), Australian Beach Pattern in order to demonstrate her understanding of the concept of "white privilege". She noted:

I really enjoyed this activity and I think it is an effective task to encourage students to consider the use of the arts as a learning tool [....]. I chose to explore the concept of white privilege as I found it to be the topic I was most passionate about and found it most challenging.

Interestingly, this participant was not the only student who chose to select an assessment concept based on what they found most confronting. Another pre-service teacher explained:

Aspects of this course that I found really difficult were actually the concepts that I wrote my previous assessments on. [...] This included the concept of the Hidden Curriculum and discrimination. [These concepts] were challenging for me to discuss but instead of being neglectful, I decided to research and make an effort to fully comprehend [.... the issues and decide how I as a teacher will remedy this in the future.

Pre-service teachers' willingness to experiment with art to help them better understand the concepts they struggled with helped show how art-based practice could be used to explicate more complicated ideas. Many students found writing about sensitive topics difficult, so the assessment based around arts practice gave them an opportunity to display concepts through an alternate form. Participants' responses revealed that by seeing how Indigenous artists were able to convey difficult 
and/or uncomfortable concepts through creative art enabled them to better understand the concepts, and illustrated how they as practioners might successfully introduce complicated ideas into their classrooms. These participants explained:

During this process I have realized how many different emotive topics could be explored with students through artist expressions. I could provide students, [.... a chance to express their emotions, their concept of the world and family, what they like and dislike and even ideas of country and culture.

I found the use of an arts-based activity allowed for further discovery of each topic $[\ldots]$ and that the further inclusion of arts based activities would work well as an 'ice breaking' assignment for first year education students.

Incorporating arts-based practices worked well in unpacking the complexity of difficult concepts. Firstly, it exposed students to Indigenous creative artists and activists, so they had Indigenous references to provide a foundation for future lessons. Secondly, it gave pre-service teachers an alternative mode of delivering difficult concepts, and they reported feeling more at ease knowing that media such as art, music or video clips could mediate the discussion. Finally, it provided pre-service teachers with opportunities to practice teaching in a relatively "safe" environment in front of their peers, and to learn from their peers' presentations and feedback.

\section{Engaging with community}


Fortnightly workshops featuring a range of guest speakers who shared their experiences were useful. For Indigenous students, guest speakers highlighted the rich value of their communities and their histories:

By listening to the guest speaker [Guest Speaker 1] talk about Indigenous past, history, art, language and community, I could see how our identities are so important to maintain and respect.

I was incredibly moved by having the opportunity to sit with an Aunty and learn about her childhood in Cherbourg ${ }^{2}$ and at the same time - very challenging.

For non-Indigenous students, guest speakers brought to life historical and contemporary events in relation to Indigenous people:

In the early weeks of the course we had [Guest Speaker 1] speak to us about her family experiences and her ancestors and wider cultural community. In being presented in the early weeks of the course, this gave me a greater understanding of how [....] history and into the present affect the Indigenous peoples.

I liked that other people's first hand experiences were drawn on [.... as this helped me understand another person's viewpoint. For example, guest speaker [1] told her story and this really helped me connect.

${ }^{2}$ An Aboriginal community north-west of Brisbane. 
Guest speakers gave all pre-service teachers ideas about ways in which the issues we discussed could be "brought to life" in their classrooms.

The speech from [Guest Speaker 2] was a highlight. I enjoyed being able to see the practical application of the theories and concepts to the classroom. It has made an impact on what and how I will teach.

Participants noted that guest speakers provided higher awareness of community members and organisations, and how they themselves could gain an understanding of the histories and perspectives of Indigenous communities. This helped to ease anxiety around introducing Indigenous perspectives into their practice because, as this participant notes, "In order to be culturally sensitive, I would seek advice from the wider community, parents and the natural environment around the school.” For many, these guest presentations heightened their confidence in being able to develop a pedagogical framework encompassing a social justice approach. However, the intensity of such learning experiences also led to recognition of the time needed to satisfactorily unpack this learning.

\section{Barriers: Structural barriers impeding growth}

Various scholars (Anderson 2011; Schick 2010; St. Denis 2007; Moreton-Robinson 2000) discuss the potential resistance white pre-service teachers may have to courses on identity and whiteness. Because of our teaching strategies, we felt reasonably prepared to support pre-service teachers through this resistance in order to engage in 
the kind of critical, and at times uncomfortable, dialogue necessary to create epistemological change (Lennon, Riley, \& Monk, 2018). Despite our preparation, there were some things outside our control and these, according to participant responses, were the most significant barriers to learning. First is the issue of having a stand-alone Indigenous Education course within the pre-service teaching programme, rather than having Indigenous considerations and knowledges woven throughout all of the courses within the programme as has been implemented in various international pre-service teachers' educations programme. The authors acknowledge that positioning Indigenous education courses in isolation can contribute to and "reinvent the settler grammars" rather than "dismantle... historical barriers to equality" (Moodie \& Patrick, 2017, 451). Further questions and discussions that arose for the authors during the planning of our Indigenous education course highlighted the extent to which settler grammars shape and position our work: Where should we place the course within the teacher education program? Will first year students be mature enough to digest the content? and Will they find the content too challenging? As an attempt to address this significant limitation of the education program, we as educators encouraged students to consider why we regarded this as a particular disadvantage of our course and invited pre-service teachers to reflect upon how they might begin to address this particular concern in their own schools and teaching practice.

Secondly, contemporary approaches to tertiary learning often incorporate flexible arrangements, with on-line components blended with on-campus classes. The course was structured so that pre-service teachers would have one week of face-toface course work followed by one week of course work online. Pre-service teachers 
reported that insufficient time for face-to-face discussion impeded their engagement and understanding of course material, as these participants explained:

I found some aspects of the course challenging in the way that we had to complete a large amount of learning about complex concepts like identity online and in a comparatively unsupported environment. [...] When we did the learning about these same concepts in the tutorial environment, I [....] was able to interpret and understand them a lot better.

Irregular contact with peers, tutors and lecturers, combined with long waits for clarification, may have contributed to the anxiety expressed by some pre-service teachers:

The activity work at home was more challenging for me personally as if there was any confusion, it would be slightly more time consuming to find out what it means. I had no quick and easy place to go to clarify what needed do be done $[\ldots]$ which made it overall more challenging.

Burke and Collier (2017) note the limitations of online learning. They state that while, “online spaces may provide potential for future critical discussions amongst distant educators $[\ldots]$ they may be more limiting in terms of the community and personal connections that are possible, and are sometimes seen as more formal and academic spaces" (238). Despite our attempts to engage students in critical dialogue around these issues, we were challenged by the structural limitations of the course, as heated discussions were often cut short due to time constraints. Pre-service teachers 
considered that reduced face-to-face time limited their opportunities to work through complex concepts, an aspect most participants rated highly. This was particularly problematic given that various researchers (DiAngelo 2011; Leonardo \& Porter 2010; Kidman et al. 2018) contend that it is precisely these kinds of critical conversations that help to ensure meaningful understandings of historical and contemporary injustices.

\section{Conclusion}

Lowenstein (2009) states that, "the viewpoints of teacher candidates need to be considered to inform and reform the efforts made by teacher educators to both address issues of diversity in teacher preparation programs and conceptualize teacher candidates as learners" (164). Our findings revealed that pre-service teachers' initial resistance towards course content varied according to how they were racially positioned in the course. While some white pre-service teachers expressed concern about offending, Indigenous pre-service teachers felt discomfort in relation to the familiarity of some of the more troubling aspects of course content dealing specifically with historical and contemporary manifestations of racism. In addition, they were aware of how the apprehension of their non-Indigenous peers could inhibit their willingness to engage in dialogue. It appears that there are unintended consequences where increased discussion of Indigenous issues impacts negatively on Indigenous students, creating a space where white students are reluctant to speak or where Indigenous students feel they must be strong advocates. This unenviable position has been imposed upon Indigenous students.

Lowenstein (2009) contends that one of the factors that may inhibit willingness to engage in courses about issues of whiteness, is teacher educators' 
unexamined perceptions of the "White teacher candidate as deficient" (163) and that this notion "may lead to pedagogies that impede their engagement" (180). She critiques modes of delivery that depend upon the "belief that ideas can be directly conveyed from one person to another" (180) and encourages teacher educators to look towards more innovative and inquiry-based approaches (Cochran-Smith et al. 2004). In this course, we utilized a number of strategies we believed could assist pre-service teachers move from passive recipients of information to active learners and educators. Participants highlighted a number of strategies that worked well, enhancing their understanding of course content and increasing their confidence in relation to teaching similar material. Strategies that decreased their resistance and increased their confidence included "making it about the students", "promoting in-class group work", “applying arts-based practice", and "engaging with the wider community".

Participants highlighted that collaborative work decreased anxiety and increased their understanding of the lived experiences of others.

Collaboratively working through sensitive issues also strengthened the teaching staff because of our own unique insights and perspectives. Like Gillespie, Ashbaugh, and DeFiore (2002), we contend that, "Being able to discuss, frankly and honestly, these issues with each other has emboldened us, both to be more critical of our own practices and to experiment with new strategies and approaches" (250). We felt that many of our students benefited from the collaborative style of the teaching team.

Through participants' responses, we learned that certain structural barriers related to course delivery within the university need to be addressed to ensure preservice teachers have time to engage in 'uncomfortable' conversations, and to interact with community members. Santoro (2009) contends that, "Without opportunities for 
both reflection and first-hand engagement with culturally diverse student groups, knowledge of self and knowledge of others cannot inform practice in effective and meaningful ways" (42). We argue that skills in critical reflection need to be taught early and often, so pre-service teachers gain confidence in their ability to teach and discuss 'sensitive' issues. However, like Lowenstein (2009), we agree that much more needs to be done, and that a single-course or single-term approach is not sufficient to ensure pre-service teachers understand and have the capacity to effectively teach issues related to Indigeneity (Burnett, et al. 2013). Such efforts need to be fully integrated into all aspects of a program, providing the tools to enhance lifelong understanding. For this to be done well, support is required at the institutional level, equipping teacher educators with the information, resources, skills and time required to ensure that pre-service teachers are truly capable of meeting the needs of an increasingly diverse student body. 


\section{References}

Ainscow, M., and Sandill, A. (2010). "Developing Inclusive Education Systems: The Role of Organisational Cultures and Leadership”. International Journal of Inclusive Education, 14 (4), 401-416.

AITSL (Australian Institute for Teaching and School Leadership). (2011). National professional standards for teachers. Melbourne: Education Services Australia.

Ah Kee, V. (2002). If I was white. Inkjet print on polystyrene board on polyvinyl chloride. Brisbane: Milani Gallery.

Anderson, C. (2011). "Impediments to Educational Success for Indigenous Students." In Two Way Teaching and Learning: Towards Culturally Reflective and Relevant Education. Edited by N. Purdie, G. Milgate, and H.R. Bell. Victoria: ACER Press.

Bennett, D., Power, A., Thomson, C., Mason, B., and Bartleet, B. "Reflection for Learning, Learning for Reflection: Developing Indigenous Competencies in Higher Education.” Journal of University Teaching \& Learning Practice, 13(2), 2016.

Available at: http://ro.uow.edu.au/jutlp/vol13/iss2/7

Bianco, M., Harris, B., Garrison-Wade, D., and Leech, N. (2011). “Gifted Girls: Gender Bias in Gifted Referrals.” Roeper Review, 33(3), 170-181. doi: 10.1080/02783193.2011.580500.

Bishop, R. (2012). "Pretty Difficult: Implementing Kaupapa Maori Theory in English-Medium Schools.” New Zealand Journal of Educational Studies, $47(2), 38-50$. 
Bond, C. (2014). "When the Object Teaches: Indigenous Academics in Australian Universities." Right Now, November (14). This file was downloaded from: http://eprints.qut.edu.au/81866/

Burke, A., and Collier, D. T. (2017). “'I Was Kind of Teaching Myself': Teachers' Conversations About Social Justice and Teaching for Change" Teacher Development, 21 (2), 269-287.

Burnett, B. M., Lampert, J., and Crilly, K. (2013). “'I Can’t Believe I Just Said That': Using Guided Reflections with Non-Indigenous Pre-Service Teachers in Australia." The International Education Journal: Comparative Perspectives, 12(1), pp. 161-179.

Dandy, J., Durkin, K., Barber, B. L., and Houghton, S. (2015). “Academic Expectations of Australian Students from Aboriginal, Asian, and Anglo Backgrounds: Perspectives of Teachers, Trainee-Teachers, and Students.” International Journal of Disability, Development and Education, 62(1), 60-82. doi: 10.1080/1034912X.2014.984591

DiAngelo, R. (2011). "White Fragility.” International Journal of Critical Pedagogy, $3: 3,54-70$.

DiGiacomo, M., Davidson, P. M., Abbott, P., Delaney, P., Dharmendra, T., McGrath, S. J., Delaney, J., and Vincent, F. (2013). "Childhood Disability in Aboriginal and Torres Strait Islander Peoples: A Literature Review” International Journal for Equity in Health, 12(1), 7.

Ford, M. (2013). “Achievement Gaps in Australia: What NAPLAN Reveals About Educational Inequality in Australia” Race Ethnicity and Education 16 (1), 80102. 
Ford, D. Y., Grantham, T.C., and Whiting, G.W. (2008). "Culturally and Linguistically Diverse Students in Gifted Education: Recruitment and Retention Issues" Exceptional Children, 74 (3), 289-306.

Francis, B., Mills, M., and Lupton, R. (2017). "Towards Social Justice in Education: Contradictions and Dilemmas" Journal of Educational Policy, 32 (4), 414431.

Gillespie, D., Ashbraugh, L., and DeFiore, J. (2002). "White Woman Teaching White Woman About White Privilege, Race Cognizance and Social Action: Toward a Pedagogical Pragmatics" Race Ethnicity and Education, 5 (3), 237-253.

Harrison, N., and Sellwood, J. (2016). Learning and Teaching in Aboriginal and Torres Strait Islander Education. Oxford: South Melbourne.

Hattie, J. (2012). Visible Learning for Teachers: Maximizing Impact on Learning. New York: Routledge.

Herbert, J. (2006) “Indigenous Learners, Language and Identity: Implications for Educators.” In Tales Out of School, edited by K. Cadman \& K. O’Regan, 7285. Special issue of Tesol in Context.

Kidman, J., Ormond, A., and MacDonald, L. (2018). "Everyday Hope: Indigenous Aims of Education in Settler-colonial Societies.” In In J. E. Petrovic \& R. M. Mitchell (Eds.), Indigenous Philosophies of Education from Around the World, (pp.228-245). New York: Routledge .

Ladson-Billings, G. (1999). "Preparing Teachers for Diverse Student Populations: A Critical Race Theory Perspective." Review of Research in Education, 24. 211247. 
Lennon, S., Riley, T., \& Monk, S. (2018). The uncomfortable teacher-student

encounter and what comes to matter. Teaching in Higher Education, 23(5), 619-630.

Leonardo, Z., and Porter, R. K. (2010). "Pedagogy of Fear: Toward a Fanonian Theory of 'Safety' in Race Dialogue." Race Ethnicity and Education, 13:2, 139-157., DOI: 10.1080/13613324.2010.482898.

Marx, S. (2006). Revealing the Invisible: Confronting Passive Racism in Teacher Education. New York: Routledge.

Marx, S. (2001). "How Whiteness Frames the Beliefs of White Female Pre-Service Teachers Working with English Language Learners of Colour.” Paper presented at the Annual Meeting of the American Educational Research Association, Seattle, WA, April 10-14, 2001.

Martin, K., and Mirraboopa, B. (2003). "Ways of Knowing, Being and Doing: A Theoretical Framework and Methods for Indigenous and Indigenist Research” In Journal of Australian Studies 27(76), 203-214. doi:10.1080/14443050309387838

McDowall, A. (2017). "(Not) Knowing: Walking the Terrain of Indigenous Education with Preservice Teachers" The Australian Journal of Indigenous Education, doi $10.1017 /$ jie.2017.10

McKenzie, P., Weldon, P., Rowley, G., Murphy, M., and McMillan, J. (2014). “Staff in Australia's Schools 2013: Main Report on the Survey 2014.” Australian Government Department of Education, Canberra. Retrieved http://research.acer.edu.au/till_misc/20

McLaughlin, J.M., and Whatman, S, L. (2015). "Beyond Social Justice Agendas: Indigenous Knowledges in Pre-Service Teacher Education and Practice in 
Australia.” In International Perspectives on Race (and Racism): Historical and Contemporary Considerations in Education and Society, edited by D. Napier, 101-120. New York: Nova Science Press.

Merriem, S.B., and Tisdell, E. (2015). Qualitative Research: A Guide to Design and Implementation (fourth ed.), San Francisco: Jossey-Bass.

Meere, C. (1940). Australian Beach Pattern. Oil on Canvas. Sydney: Art Gallery NSW

Mills, C., and Ballantyne, J. (2016). "Social Justice and Teacher Education: A Systematic Review of Empirical Work in the Field." Journal of Teacher Education, 67 (4), 263-276.

Moodie, N., and Patrick, R. (2017). "Settler grammars and the Australian professional standards for teachers." Asia-Pacific Journal of Teacher Education, 45 (5), 439-454.

Moreton-Robinson, A. (2000) Talkin' Up to the White Woman: Indigenous Women and Feminism. Brisbane: UQ Press.

Nakata, M., Nakata, V., Keech, S., and Bolt, R. (2012). "Decolonial Goals and Pedagogies for Indigenous Studies" Decolonization, Indigeneity, Education \& Society, 1(1), 120-140.

Nakata, M. (2007). "The Cultural Interface” The Australian Journal of Indigenous Education, 36, 7-14.

Pidgeon, M. (2016). "More Than a Checklist: Meaningful Indigenous Inclusion in Higher Education" Social Inclusion, 4 (1). 77-91.

Riley, T. (2014). Raising Awareness to Transcend Disciplines: Raising Teachers' critical Awareness Across Disciplines to Increase Indigenous Learner Engagement. Australian Journal of Indigenous Education. 43 (2), 144-153. 
Riley, T. (2018). Exceeding expectations: Teachers' decision making regarding Aboriginal and Torres Strait Islander Students. Doi: $10.1177 / 0022487118806484$

Riley, T. \& Pidgeon, M. (2018). "Australian teachers voice their perceptions of the influences of stereotypes, mindsets and school structure on teachers' expectations of Indigenous students" Teaching Education, https://doi.org/10.1080/10476210.2018.1453796

Rose, M. (2012). The Silent Apartheid as the Practitioner's Blind Spot. In Aboriginal and Torres Strait Islander Education: An Introduction for the Teaching Profession, edited by K. Price, 66-81). Port Melbourne, Vic: Cambridge University Press.

Rubie-Davies, C, Hattie, J, and R. Hamilton. (2006). "Expecting the Best for Students: Teacher Expectations and Academic Outcomes" British Journal of Educational Psychology, 76, 429-444. doi:101.1348/000709905X5389

Rubie-Davies, C., and Peterson, E. (2016). 'Relations Between Teachers' Achievement, Over and Underestimation, and Students' Beliefs for Maori and Pakeha Students" Contemporary Educational Psychology, 47, 72-83.

Rubin, I. J., and Rubin, I. S. (2005). Qualitative Interviewing: The Art of Hearing Data (2nd ed.). London: Sage.

Santoro, N. (2009). "Teaching in Culturally Diverse Contexts: What Knowledge About 'Self' and 'Others' Do Teachers Need?' Journal of Education for Teaching: International Research and Pedagogy, 35 (1), 33-45.

Sarra, C. (2011). Strong and Smart - Towards a Pedagogy for Emancipation: Education for First Peoples. New York: Routledge. 
Sarra, C. (2003). Young and Black and Deadly: Strategies for Improving Outcomes for Indigenous Students. Deakin West, ACT: Australian College of Educators.

Schick, C. (2014). "White Resentment in Settler Society" Race Ethnicity and Education, 17 (1), 88-102.

Schick, C. (2000). “White Woman Teachers Accessing Dominance” Discourses: Studies in the Cultural Politics of Education, 21(3), 299-309.

Schick, C., and St. Denis, V. (2005). “Troubling National Discourses in Anti-Racist Curricular Planning” Canadian Journal of Education, 28 (3), 295-317.

Schick, C. (2010). “'By Virtue of Being White': Resistance in Anti-Racist Pedagogy” Race, Ethnicity and Education. Volume 3, 2000 - Issue 1.

Schneidewind, N., and Davidson, E. (2014). Open minds to Equality: A sourcebook of learning activities to affirm diversity and promote equity, Fourth Edition. New York: Rethinking Schools.

St. Denis, V. (2007). “Aboriginal Education and Anti-Racist Education: Building Alliances Across Cultural and Racial Identity" Canadian Journal of Education, 30 (4). 1068-1092.

St. Denis, V. (2011). "Silencing Aboriginal Curricular Content and Perspectives Through Multiculturalism: 'There Are Other Children Here'” Review of Education, Pedagogy, and Cultural Studies, 33(4), 306-317. doi: $10.1080 / 10714413.2011 .597653$

Strauss, A., and Corbin, J. (1998). Basics of Qualitative Research Techniques. Thousand Oakes, CA: Sage.

Sutton Trust. (2015). Subject to Background. London: Sutton Trust 
Sweller, N., Graham, L. J., and Van Begen, P. (2012). “The Minority Report: Disproportionate Representation in Australia's Largest Educational System” Exceptional Children, 79(1), 107-125.

Tatum, B.D., (1999). “Why Are All the Black Kids Sitting Together in the Cafeteria?” And Other Conversations About Race. New York: Basic Books.

Turhan, M. (2010). “Social Justice Leadership: Implications for Roles and Responsibilities of School Administrators" Procedia Social and Behavioral Sciences. Vol. 9, 1357-1361.

Van Issum, H. (2012) Why We Need Aboriginal and Torres Strait Islander Perspectives: Understanding the Teaching and Learning of Geography and History in Place and Time: Explorations in Teaching Geography and History. Taylor, Fahey, Kriewaldt \& Boon (Eds.) Pearson: Frenchs Forest.

Van Issum, H. (2019) Why We Need Aboriginal and Torres Strait Islander Perspectives in Place and Time: Teaching History, Geography and Social Sciences. (2 ${ }^{\text {nd }} E d n$.) Taylor, Fahey, Kriewaldt \& Boon (Eds.) Pearson: Frenchs Forest.

Weldon, P.R. (2015). The Teacher Workforce in Australia: Supply, Demand and Data Issues. Australian Council for Educational Research. Available: https://research.acer.edu.au/cgi/viewcontent.cgi? article=1001\&context=policy insights 